Revista

\title{
Multi-Ensayos
}

Vol. 4, $\mathrm{N}^{\circ} 7$

ISSN: 2412-3285

https://multiensayos.unan.edu.ni

DOI: https://doi.org/10.5377/multiensayos.v4i7.9485

\section{Cultura Organizacional, elemento clave para el éxito del desempeño profesional de un estudiante de Administración de Empresas}

\section{Organizational Culture, key element for the success of the professional performance of a student of Business Administration}

\author{
Ángela Patricia Rodríguez Pérez ${ }^{1}$
}

Recibido: 02 de abril de 2018, Aceptado: 18 de octubre de 2018

\section{RESUMEN}

El desarrollo de la cultura organizacional en una empresa, permite a los integrantes de las organizaciones ciertas conductas e inhiben otras. Una cultura laboral abierta y humana alienta la participación y conducta de todos los miembros de la organización, sí las personas se comprometen y son responsables, se debe a que la cultura laboral se lo admite. Además, permite que una organización sea diferente a las demás, debido a que todas esas prácticas y tradiciones se mantienen particularmente dentro de esa organización y por esta razón se puede crear un sentido de pertenencia, identificar a los trabajadores y que ellos mismo se sientan únicos entre otros: "Uno de los elementos que caracterizan hoy a las organizaciones es su cultura".

Palabras claves: cultura organizacional; tipos; elementos.

\section{ABSTRACT}

The development of the organizational culture in a company allows the members of the organizations to perform certain behaviors and inhibit others. An open and humane work culture encourages the participation and behavior of all the members of the organization, if people are committed and responsible, it is because the work culture admits it. Also, it allows an organization to be different from the others, because all those practices and traditions are kept particularly within that organization and for this reason you can create a sense of belonging, to identify the workers and to allow them to feel unique among others: "One of the elements that characterize organizations today is their culture".

Keywords: organizational culture; types; elements.

1 Docente del Departamento de Ciencias Económicas y Administrativas, UNAN-Managua/FAREM-Estelí. Correo electrónico: elegante2mayo@gmail.com

Copyright (c) 2018 Revista Multi-Ensayos. 


\section{INTRODUCCIÓN}

El presente ensayo aborda la importancia de la cultura organizacional para un estudiante egresado de la carrera de Administración de Empresas en la Universidad Autónoma de Nicaragua, Managua (UNANManagua).

La cultura organizacional es un grupo complejo de valores, tradiciones, políticas, supuestos, comportamientos y creencias esenciales que se manifiesta en los símbolos, los mitos, el lenguaje, los comportamientos constituye un marco de referencia compartido para todo lo que se hace y se piensa en una organización. Por ser un marco de referencia, no atiende cuestiones puntuales, sino que establece las prioridades y preferencias acerca de lo que es esperable por parte de los individuos que la conforman. (Chiavenato, Comportamiento Organizacional, 2009)

El objetivo del presente ensayo es reflexionar sobre la cultura organizacional como elemento clave para el éxito del desempeño profesional de un estudiante de Administración de Empresas. Dicha cultura permite que una organización sea diferente a las demás, debido a que todas esas prácticas y tradiciones se mantienen particularmente dentro de esa organización y por esta razón se puede crear un sentido de pertenencia, identificar a los trabajadores y que ellos mismo se sientan únicos.

\section{DESARROLLO}

La cultura organizacional es la médula espinal de cualquier organización que quiera llegar al éxito, se puede decir que es la esencia del aprendizaje y la experiencia, esta no puede ser impuesta solo puede ser aprendida. La misma, refleja los valores, creencias y actitudes que han aprendido y comparten sus miembros.

Dentro de las funciones de la cultura organizacional es la de dar a los miembros una identidad organizacional, esto se puede llevar a cabo mediante reconocimientos a empleados que se esfuerzan por ser más productivos, pues ayudan a la empresa a obtener mayores beneficios y que la organización sea exitosa.

Las organizaciones deben dedicar recursos que energicen a sus propios colaboradores| organizacionales. Y uno de los papeles clave en el desarrollo de una cultura organizacional tiene que ver con el liderazgo. Una de las funciones más importante de un líder consiste en manejar el cambio cultural necesario para sostener el crecimiento de la organización en el tiempo.

La cultura organizacional que tiene que ver con las aptitudes, expectativas, necesidades, motivos y actitudes desarrolladas por cada una de las personas basada sobre experiencias que han sido interpretadas en una forma particular, vivenciadas durante sus primeros años en la empresa. (Schein, 1988), cita el caso de un joven graduado que haciendo uso del ancla de competencia gerencial renunció a su empresa a pesar de que sus superiores estaban contentos con su performance; ¡esto se debió a que el mismo graduado consideraba que solamente trabajaba en realidad unas dos horas al día! Es muy usual que el ancla de carrera sea la competencia técnica o profesional de la persona; muchos no alcanzan su potencial cuando 
son transferidos de una función profesional a una función gerencial, y al verse forzado al nuevo rol puede comenzar a desarrollar acciones que lo expulsen o se auto expulse de la empresa.

La importancia de una cultura fuerte, en organizaciones de alto desempeño y que sobreviven y crecen en ambientes donde el cambio es la constante y la competencia mayor. Ha estado fuertemente interesado en producir mejoras tanto a nivel individual como grupal y organizacional, y mostrado fuertes competencias y habilidades en trabajar a través de estas distintas unidades de análisis.

Tipos de cultura organizacional

1. Cultura burocrática: practica las reglas, procedimientos de operación estándar y una coordinación jerárquica. características de la burocracia son: la previsibilidad, la eficiencia y la estabilidad.

2. Cultura del clan: constituida por la tradición, la lealtad, el compromiso personal, una amplia socialización, el trabajo en equipo, la auto dirección y la influencia social.

3. Cultura emprendedora: la caracterizan los altos grados de creatividad y disposición de asumir riesgos.

4. Cultura de mercado: la caracterizan el logro de metas mensurables y exigentes, sobre todo financieras y las basadas en el mercado (por ejemplo, el crecimiento de ventas, la rentabilidad y la participación de mercado).

5. En general es posible identificar, al menos, dos subsistemas culturales en una organización:

\section{La cultura formal}

Que consiste en expresiones idealizadas de lo que debería ser, de los valores, creencias y el comportamiento de los miembros.

\section{La cultura informal}

Que contiene los comportamientos como son en realidad.

En ocasiones, estas dos culturas chocan entre ellas y con la cultura general de la organización; en este sentido, Deal y Kennedy, 1985; indican varios aspectos importantes:

- La endogamia cultural, que se produce cuando no hay intercambio formal o informal entre las culturas.

- Los choques entre subculturas, aunque sea deseable una sana tensión entre ellas, si se torna muy pronunciada, se vuelve nociva y puede suponer un problema.

- La exclusividad, cuando la subcultura asume los requisitos de los clubes selectos, impone restricciones para pertenecer a ellos, se producen exclusiones arbitrarias de algunos individuos, etcétera.

- Las jerarquías subculturales, cuando los valores de las subculturas tienen prioridad sobre los valores compartidos de la empresa.

Respecto a los elementos integrantes de la cultura organizativa, (Schein, 1988) distingue 3 niveles:

- Producciones. Es el más visible e incluye el espacio físico, capacidad tecnológica, lenguaje, conducta observada en los miembros de una organización, producciones artísticas; en general, se compone de todos aquellos elementos que pueden captarse con nuestros sentidos.

- Valores. Es decir, los que la organización y sus miembros piensan que deben ser, en función de lo cual 
actúan de una u otra manera.

- Formado por una serie de presunciones básicas, invisibles y preconscientes que se dan por sentadas. son cuestiones indiscutibles y asimiladas por el personal, que piensa que determinadas cosas son así porque no pueden ser de otro modo.

Toda organización trata de vender su imagen y de transmitirla al exterior, para ello, se valen de los siguientes elementos:

- Logotipos: para transmitir sensaciones de dinamismo o estabilidad, mediante el uso de imágenes, movimientos, colores, etcétera.

- Eslogan: mediante el uso del lenguaje la empresa puede decir mucho sobre ella.

- La distribución del espacio en los edificios: su decoración y mobiliario, pueden transmitir la ideología de una institución, si es conservadora o no, moderna, tradicional, etcétera.

La cultura no sólo incluye valores, actitudes y comportamientos, sino también la visión, las estrategias y las acciones, que en conjunto funcionan como sistema dinámico.

La cultura es la forma acostumbrada o tradicional de pensar y hacer las cosas, compartidas en mayor o menor medida por los miembros de una organización. Determina la forma en que funciona una empresa; se refleja en las estrategias, estructuras y sistemas establecidos a lo largo de años de funcionamiento y se identifica con los sistemas dinámicos de la organización, porque los valores pueden modificarse, como efecto del aprendizaje continuo de los individuos.

Es la cultura organizacional la que define el comportamiento, motiva a sus integrantes y afecta la forma en que la organización procesa la información. La combinación de diversos factores muestra las bases de la cultura organizacional, tal es el caso del uso de la información y su diseminación, el uso del correo electrónico, de los informes; así como la preferencia por la información oral, los rumores, etcétera.

La cultura organizacional es la médula de la organización, es la fuente invisible donde la visión adquiere su guía de acción. El éxito de los proyectos de transformación depende del talento y de la actitud de la gerencia para cambiar la cultura de la organización de acuerdo con las exigencias del entorno.

Según Charles Handy (1987), pueden distinguirse cuatro tipos de culturas organizacionales en dependencia del énfasis que se conceda a algunos de los siguientes elementos: poder, rol, tareas y personas. La cultura del poder se caracteriza por estar dirigida y controlada desde un centro de poder ejercido por personas clave en las organizaciones.

La cultura basada en el rol se identifica frecuentemente con la burocracia y se sustenta en una clara y detallada descripción de las responsabilidades de cada puesto en la organización. La cultura por tareas se soporta fundamentalmente en el trabajo proyectos que realiza la organización y se orienta hacia la obtención de resultados específicos en tiempos concretos. Finalmente, la cultura centrada en las personas, como su nombre lo indica, se basa en los individuos que integran la organización. 
La cultura organizacional tiene una importancia indiscutible en la conformación de una estrategia. Por ejemplo, si la organización se encuentra en un ambiente muy dinámico y de gran competencia, se necesita una cultura que apoye la flexibilidad y la coordinación de esfuerzos. Cuando la cultura se corresponde con la estrategia puede decirse que ella se encuentra en su mejor condición. Para una vida duradera, es determinante que la cultura se corresponda con la estrategia.

La cultura se identifica con los sistemas dinámicos de la organización, porque los valores pueden modificarse como resultado del aprendizaje continuo de los individuos; además, se concede gran importancia a los procesos de sensibilización al cambio como elemento puntual de la cultura organizacional.

La cultura determina lo que las personas involucradas en ella consideran correcto o incorrecto, así como sus preferencias en la manera de ser dirigidos. Tiene la particularidad de manifestarse por medio de conductas significativas de los miembros de una organización, las cuáles facilitan el comportamiento en ella y, se identifican mediante un conjunto de prácticas gerenciales y supervisoras, como elementos de la dinámica organizacional.

\section{CONCLUSIONES}

Se puede concluir diciendo que la cultura organizacional es dinámica, evolutiva y se crea mediante la interacción de los elementos como individuos, grupos, equipos, lideres, normas, estructura de los roles, relaciones con el contexto, aprendizajes organizacionales de éxitos y fracasos.

Un profesional egresado de la carrera de administración de empresas en la Universidad Nacional Autónoma de Nicaragua, Managua, debe saber que la cultura organizacional, es una fortaleza que encamina a las organizaciones hacia la excelencia, el éxito y que cada empresa es única debido a que todas esas prácticas y tradiciones se mantienen particularmente dentro de esa organización y por esta razón se puede crear un sentido de pertenencia, identificar a los trabajadores y que ellos mismo se sientan únicos.

De esta manera se puede ver que los cambios del panorama mundial las organizaciones que hoy enfrentan el reto de adoptar una cultura organizacional que no solo sea flexible, si no también sensible a las muchas diferencias culturales que enfrentan los miembros de la organización dentro de las sociedades y entre ellas.

\section{BIBLIOGRAFÍA}

Chiavenato, I. (2007). Administracion de Recursos Humanos. El capital Humano en las Organizaciones (Octava ed.). México D.F: McGraw Hill.

Chiavenato, I. (2009). Comportamiento Organizacional (Segunda Edición ed.). México: McGraw Hill.

Schein, E. H. (1988). Cultura Organizacional y Liderazgo (Tercera edición ed.).

Stephen P. Robbins, T. A. (2009). Comportamiento Organizacional (Decimotercera edición ed.). México D.F, México: Prentice Hall. 